\title{
PD-1 and PD-L1 Up-regulation Promotes T-cell Apoptosis in Gastric Adenocarcinoma
}

\author{
YING-MING CHIU $^{1,2^{*}}$, CHUNG-LIN TSAI $^{3,4^{*}}$, JUNG-TA KAO $^{3,5}$, CHIN-TUNG HSIEH $^{6}$, \\ DONG-CHEN SHIEH ${ }^{2}$, YI-JU LEE ${ }^{7}$, GREGORY J. TSAY ${ }^{8,9}$, KEN-SHENG CHENG $^{10}$ and YI-YING WU ${ }^{11}$ \\ ${ }^{1}$ Division of Allergy, Immunology \& Rheumatology, Changhua Christian Hospital, Changhua, Taiwan, R.O.C.; \\ ${ }^{2}$ Department of Nursing, College of Medicine \& Nursing, Hungkuang University, Taichung, Taiwan, R.O.C.; \\ ${ }^{3}$ Graduate Institute of Clinical Medical Science, China Medical University, Taichung, Taiwan, R.O.C.; \\ ${ }^{4}$ Division of Cardiovascular Surgery, Taichung Veterans General Hospital, Taichung, Taiwan, R.O.C.; \\ ${ }^{5}$ Department of Internal Medicine, School of Medicine, \\ China Medical University Hospital and China Medical University, Taichung, Taiwan, R.O.C.; \\ ${ }^{6}$ Department of Pediatrics, Lotung Poh-Ai Hospital, I-Lan, Taiwan, R.O.C.; \\ ${ }^{7}$ Institute of Biochemistry, Microbiology and Immunology, \\ Chung Shan Medical University, Taichung, Taiwan, R.O.C.; \\ ${ }^{8}$ Division of Immunology and Rheumatology, Department of Internal Medicine, \\ China Medical University Hospital, Taichung, Taiwan, R.O.C.; \\ ${ }^{9}$ School of Medicine, College of Medicine, China Medical University, Taichung, Taiwan, R.O.C.; \\ ${ }^{10}$ Department of Internal Medicine, Division of Hepato-Gastroenterology, \\ China Medical University Hospital, Taichung, Taiwan, R.O.C.; \\ ${ }^{11}$ Department of Medical Laboratory Science and Biotechnology, \\ China Medical University, Taichung, Taiwan, R.O.C.
}

\begin{abstract}
Background/Aim: The programmed death 1 $(P D-1)$ receptor and its ligand $(P D-L 1)$ play pivotal roles in regulating host immune responses. However, the inhibitory effects of this pathway on the function of tumor infiltrating T lymphocytes in gastric adenocarcinoma patients are not well-defined. Materials and Methods: We characterized the expression of $P D-1$ and $P D-L 1$ in peripheral blood and tumor infiltrating cells and analyzed the association between PD-1/PD-L1 expression and disease progression in a cohort of 60 patients with Helicobacter pylori infection, including 18 with gastric adenocarcinoma, 23 with gastritis, and 19 asymptomatic controls. Results: Relative to controls, the expression of PD-1 on peripheral blood and tumor infiltrating $T$ cells increased with disease progression. In
\end{abstract}

*These Authors contributed equally to this study.

Correspondence to: Yi-Ying Wu, Department of Medical Laboratory Science and Biotechnology, China Medical University, No. 91, Hsueh-Shih Rd., Taichung 404, Taiwan. Tel: +886 422053366, ext. 7228, Fax: +886 422057414, e-mail: yyw@mail.cmu.edu.tw

Key Words: Gastric adenocarcinoma, PD-1, PD-L1, Helicobacter pylori, apoptosis. vitro, $T$ cells induced PD-L1 expression on primary gastric adenocarcinoma epithelial cells in an IFN- $\gamma$-dependent manner, which in turn promoted T cells apoptosis. Blocking of PD-L1 reversed this effect. Conclusion: This study provides evidence for a new therapeutic target in gastric adenocarcinoma patients.

Gastric cancer is the fifth most common cancer and is the third leading cause of cancer-related death worldwide (1). Surgical treatment is currently the only option which offers curative potential. For metastatic disease patients, conventional chemotherapy has shown only a modest benefit in metastatic disease with an average survival of approximately ten months (2). Many mechanisms have been proposed to explain attenuated immune response to tumors, including partial antigen masking, failure of antigen processing, suppression of effector cells, and inadequate costimulation.

Programmed death 1 (PD-1), a member of the immunoglobulin superfamily, can be detected on activated $\mathrm{T}$ cells, B cells and natural killer (NK) cells (3) and plays a crucial role in regulating peripheral tolerance (4). PD-L1, the ligand of PD-1, constitutively exists on T and B cells, DCs, macrophages, mesenchymal stem cells, and bone marrowderived mast cells (5). PD-1/PD-L1 pathway suppress anti- 
tumor immunity and promotes tumor progression by inactivating $\mathrm{T}$ cells, protecting tumor cells, and activating tumor-suppressive cell populations (6) and blockade of this pathway by employing anti-PD-L1 antibodies, enhances antitumor immunity and inhibits tumor growth in several human cancers (7-9). In addition, among patients with hepatocellular carcinoma, pancreatic cancer, urothelial cancer, breast, or ovarian cancer, patients with PD-L1-positive cancer cells were reported to have a significantly poorer prognosis than those with PD-L1-negative cancer cells (9-13).

However, the changes in function of tumor infiltrating $\mathrm{T}$ cells underlying the immunosuppressive effects mediated by the PD-1/PD-L1 pathway remain to be clarified in patients with gastric adenocarcinoma. Thus, in the present study we explored and compared the interactions between PD-1/PD-L1 in gastric adenocarcinoma epithelial cells with those in $\mathrm{T}$ cells and determined whether this pathway is associated with clinical prognosis and immune suppression of anti-tumor $\mathrm{T}$ cells.

\section{Materials and Methods}

Subjects and patients. Biopsy specimens were obtained from patients undergoing gastric endoscopy at China Medical University Hospital; informed consent was obtained from all patients. The study was approved by the Medical Ethics Committee of China Medical University Medical Center (Taichung, Taiwan) (CMUH102-REC2009). A total of 3-4 biopsy specimens were obtained from each patient. Moreover, peripheral blood samples from the same patients served as the control. There were 18 gastric adenocarcinomas, 19 asymptomatic controls, 23 gastritis patients enrolled in this study.

Cell culture. Human primary gastric adenocarcinoma epithelial cells were cultured using a previously described method (14-18). In brief, gastric adenocarcinoma biopsy specimens were collected in Leibowitz's L-15 medium (Life Technologies, Grand Island, NY, USA). Gastric adenocarcinoma cells were isolated enzymatically using collagenase/dispase after the tissue had been mechanically minced into $\leq 1-\mathrm{mm}$ pieces. The tissue was then pelleted by centrifugation at $1,500 \mathrm{rpm}$ for $5 \mathrm{~min}$ at $4^{\circ} \mathrm{C}$ and the collagenase/dispase was discarded. The tissue was then washed once in $10 \mathrm{ml}$ of phosphate-buffered saline and pelleted by centrifugation. Cells were resuspended in the cell culture medium. Gastric adenocarcinoma epithelial cells obtained as described above were suspended in $2 \mathrm{ml}$ of Ham's F-12 cell culture medium (Life Technologies, Grand Island, NY, USA) with $10 \%$ fetal bovine serum and placed into a six-well tissue culture plate. Approximately $48 \mathrm{~h}$ after being placed in culture, primary human gastric adenocarcinoma epithelial cells were stained with antibodies to cytokeratin 18 (Sigma Chem., St. Louis, MO, USA) to test for purity (19). The cytoplasm of virtually every cell in the colony stained positive for cytokeratin 18 , indicating that these cells were of epithelial origin. MTT reduction assay (Chemicon International Inc, Temecula, California, USA) at 48 hours revealed that the viability of the epithelial cells was $>95 \%$.

Cell isolation. Peripheral blood mononuclear cells (PBMC) were isolated from heparinized blood by Ficoll-Hypaque (Pharmacia, Uppsala, Sweden) density gradient centrifugation.
Tumor infiltrating lymphocytes (TIL) and non-tumor infiltrating lymphocytes that had been taken $5-10 \mathrm{~cm}$ distal from the tumor site (NIL) were isolated as previously reported (16-18). $\mathrm{CD}^{+} \mathrm{T}$ cells were isolated from PBMC by using CD3 Microbeads (Miltenyi Biotec, Auburn, CA, USA). All procedures were performed according to the manufacturers' instructions.

Flow cytometry analysis. Antibodies conjugated with different fluoresceins, including fluorescein isothiocyanate (FITC), phycoerythrocin (PE), peridinin chlorophyll protein (PerCP) and allophycocyanin (APC) were employed for flow cytometry analysis (FACS Calibur, BD Biosciences, San Jose, CA, USA). All antibodies were purchased from BD Biosciences (San Jose, CA, USA), except for PE-conjugated PD-1 and PD-L1 (eBiosciences, San Diego, CA, USA) and FITC-conjugated CCR7 (R\&D Systems, Minneapolis, MN, USA). PD-1 expression on CD3 ${ }^{+} \mathrm{T}$ cells and on their memory subsets and intracellular IFN $-\gamma$ staining assay were analyzed by flow cytometry as previously described $(16,17)$.

Proliferation assay. PBMC were cultured in complete RPMI 1640 medium with $10 \%$ fetal bovine serum (Gibco, Carlsbad, CA, USA) and stimulated with anti-CD3 and CD28 monoclonal antibodies (mAbs). The cells were seeded in a 96-well plate (Costar, Lowell, MA, USA) in the presence or absence of anti-human PD-L1 ( $\alpha$-PDL1). Cells were harvested at 3, 5, or 7 days. BrdU incorporation was measured using an enzyme-linked immunosorbent assay with chemiluminescence detection (Roche Molecular Biochemicals, Mannheim, Germany) and a luminescence counter (TopCount; Packard Instruments, Meriden, CT). The counts per second correlated directly to the amount of DNA synthesis and the number of proliferating cells.

$P D-L 1$ up-regulation by IFN- $\gamma$ stimulation. Human primary gastric adenocarcinoma epithelial cells were cultured in the presence of IFN- $\gamma\left(25 \mathrm{ng} / \mathrm{ml}\right.$, Peprotech Inc.) or co-cultured with CD3 ${ }^{+} \mathrm{T}$ cells from gastric adenocarcinoma patients at a ratio of $1: 1$. Cells were seeded in the presence or absence of anti-IFN- $\gamma$ mAbs $(5 \mu \mathrm{g} / \mathrm{ml}$, R\&D). After $3,6,9,12$ or $24 \mathrm{~h}$, the cells were harvested to analyze PD-L1 expression on primary gastric adenocarcinoma epithelial cells by flow cytometry.

Cytotoxicity assay. Primary gastric adenocarcinoma epithelial cells were used as the target cells for the cytotoxicity assay. The effector $\mathrm{CD}^{+} \mathrm{T}$ cells for this assay were collected from patients with gastric adenocarcinoma. Before the assay, primary gastric adenocarcinoma epithelial cells were treated in the presence (treated) or absence (untreated) of IFN- $\gamma(25 \mathrm{ng} / \mathrm{ml})$ for $24 \mathrm{~h}$. Isolated CD3 $3^{+} \mathrm{T}$ cells were co-cultured with treated or untreated primary gastric adenocarcinoma epithelial cells at ratios of $3: 1,6: 1,12: 1$, or $24: 1$ in the presence or absence of $\alpha$-PD-L1 $(5 \mu \mathrm{g} / \mathrm{ml})$. After 6 hours of incubation, the cells were harvested and stained with 7-AAD (Invitrogen, Carlsbad, CA, USA) before flow cytometric analysis.

Apoptosis assay. IFN- $\gamma$-treated or untreated primary gastric adenocarcinoma epithelial cells were co-cultured with $\mathrm{CD} 3^{+}+\mathrm{T}$ cells that had been isolated from gastric adenocarcinoma patients at ratios of $1: 1,5: 1$ or $10: 1$ in the presence or absence of $\alpha$-PD-L1. After $24 \mathrm{~h}$ of incubation, the cells were harvested and stained with Annexin-V-FITC or 7-AAD (eBiosciences, San Diego, CA, USA) to analyze the apoptosis or necrosis of $\mathrm{CD}^{+} \mathrm{T}$ cells respectively. 
ELISA. Tumor or non-tumor biopsy specimens were ground in PBS using the BD Medmachine (BD Biosciences, San Jose, CA, USA) according to the manufacturer's instructions. Supernatants from the homogenates were subjected to ELISA for IFN- $\gamma$ detection (eBiosciences, San Diego, CA, USA). The final results were normalized to picograms per gram of tissue $(\mathrm{pg} / \mathrm{g})$.

Immunohistochemistry. Paraffin-embedded sections of gastric adenocarcinoma and non-tumor tissues $(5-10 \mathrm{~cm}$ distal from the tumor site), and biopsy specimens of the antrum or gastric body from patients with gastritis and from asymptomatic patients with Helicobacter pylori were used for immunohistochemical staining. All sections were obtained from clinical units of our hospital and were independent from the enrolled subjects mentioned above. The mAbs of mouse anti-human PD-1 (R\&D, Minneapolis, MN, USA), mouse anti-human PD-L1 (Biolegend, San Diego, CA, USA) and mouse anti-human cleaved-caspase-3 (Zhongshan Goldenbridge Biotech, Beijing, China) were used for PD-1, PD-L1 and cleavedcaspase-3 staining respectively.

Statistical analysis. The data are presented as mean \pm standard deviation. Comparisons between gastric adenocarcinoma, gastritis, and normal control groups were performed using the Mann-Whitney $U$-test. The Wilcoxon matched-pair $t$-test was used to compare the data from the same individuals. Correlation analysis was performed using the Spearman rank correlation test. For all tests, a $p<0.05$ was considered to indicate statistical significance. All statistical analyses were performed with the statistical package SPSS for Windows (SPSS Inc, Chicago, IL, USA).

\section{Results}

$P D-1$ expression is up-regulated on effector-phase $C D 3^{+} T$ cells in gastric adenocarcinoma patients, especially in tumor infiltrating lymphocytes. We first analyzed the expression of PD-1 on $\mathrm{CD}^{+} \mathrm{T}$ cells. The results showed that the level of PD-1 expression on peripheral blood $\mathrm{CD}^{+} \mathrm{T}$ cells was higher in patients with gastric adenocarcinoma than in patients with gastritis or asymptomatic controls. Furthermore, the expression of PD-1 on $\mathrm{CD}^{+} \mathrm{T}$ cells in tumor infiltrating lymphocytes was significantly higher than that in the corresponding PBMC and non-tumor infiltrating lymphocytes (Figure 1A and B). We further analyzed PD-1 expression on different $\mathrm{CD}^{+} \mathrm{T}$ cell subsets based on CCR7 and CD45RA expression. The PD-1 expression on $\mathrm{CD}^{+} \mathrm{T}$-cell subsets in gastric adenocarcinoma differed from that in normal controls and in gastritis patients and predominantly increased on effector-phase $\mathrm{T}$ cells, including $\mathrm{CCR} 7^{+} \mathrm{CD} 45 \mathrm{RA}{ }^{-}(\mathrm{Tcm})$ and $\mathrm{CCR}^{-}{ }^{-} \mathrm{CD} 45 \mathrm{RA}^{-}$(Tem) (Figure 1C). Furthermore, PD-1 was greater on each subset than in non-tumor infiltrating lymphocytes particularly in tumor infiltrating lymphocytes $(p<0.05)$. These data indicate that PD-1 is preferentially increased on effector-phase $\mathrm{CD}^{+} \mathrm{T}$ cells in gastric adenocarcinoma, especially in tumor infiltrating lymphocytes.

The in situ expression of PD-1/PD-L1 by immunohistochemical staining. We also explored the in situ expression levels of PD-
A

Isotype control Normal PBMC Gastritis PBMC

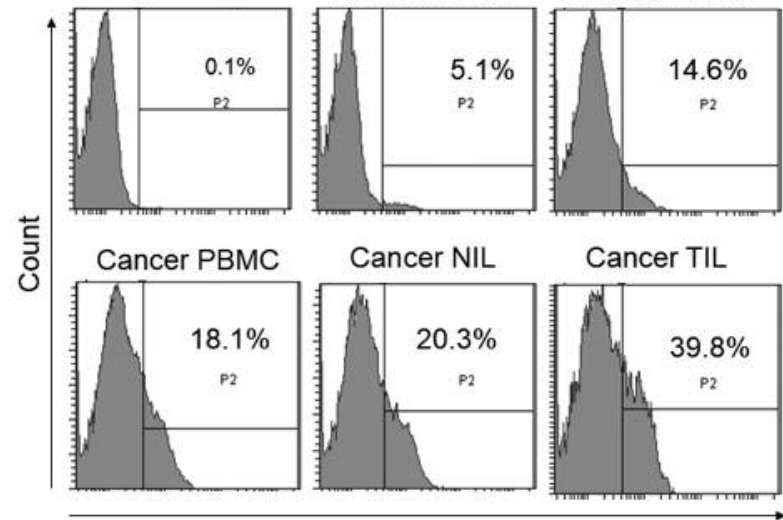

PD-1
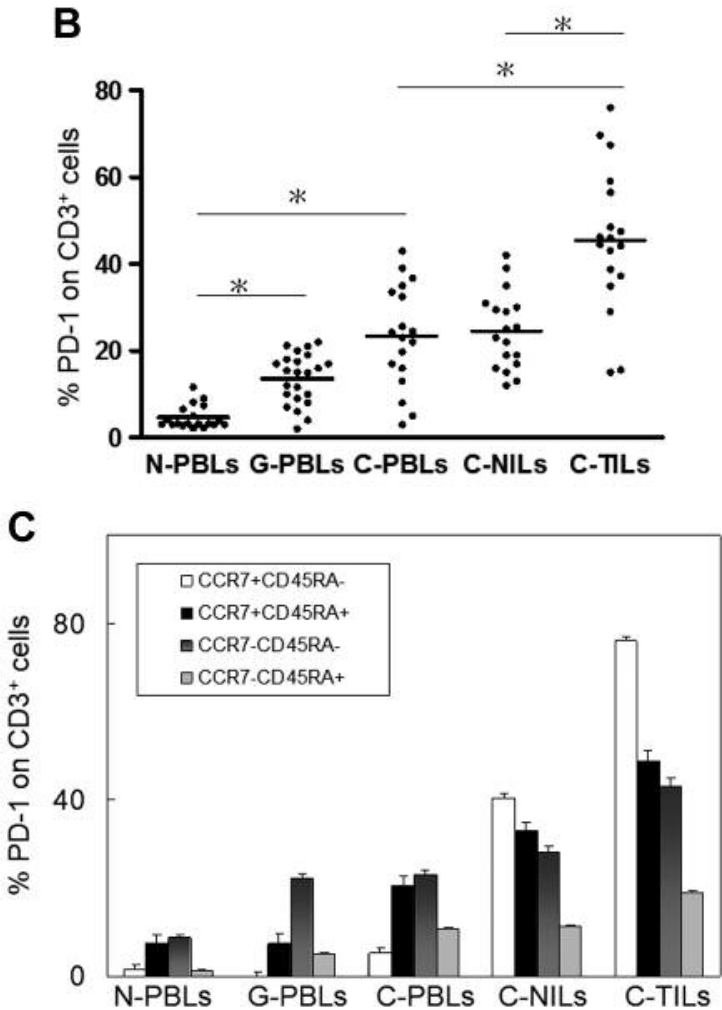

Figure 1. Overexpression of $P D-1$ on effector-phase $C D 3^{+} T$ cells in peripheral blood and stomach tissue in gastric adenocarcinoma patients. Representative histograms (A) and combined results with statistical analysis $(B)$ of $P D-1$ expression on $C D 3^{+} T$ cells in peripheral blood of asymptomatic controls $(n=19)$, patients with gastritis $(n=23)$, and patients with gastric adenocarcinoma $(n=18)$, and in corresponding nontumor infiltrating lymphocytes (NIL) and tumor infiltrating lymphocytes (TIL). For (A), the number in the upper right corner is the percentage of positive cells. For (B), each dot indicates one individual. Black bars in the graph represent mean values of \% PD-1 expression on $C D 3^{+} T$ cells. $(C)$ Representative histograms of $P D-1$ expression on different $C D 3^{+} T$-cell subsets in peripheral blood and corresponding NIL and TIL. Different memory subsets are distinguished by CCR7 and CD45RA. (A). The data are representative of five subjects in each group. ${ }^{*} p<0.05$. 

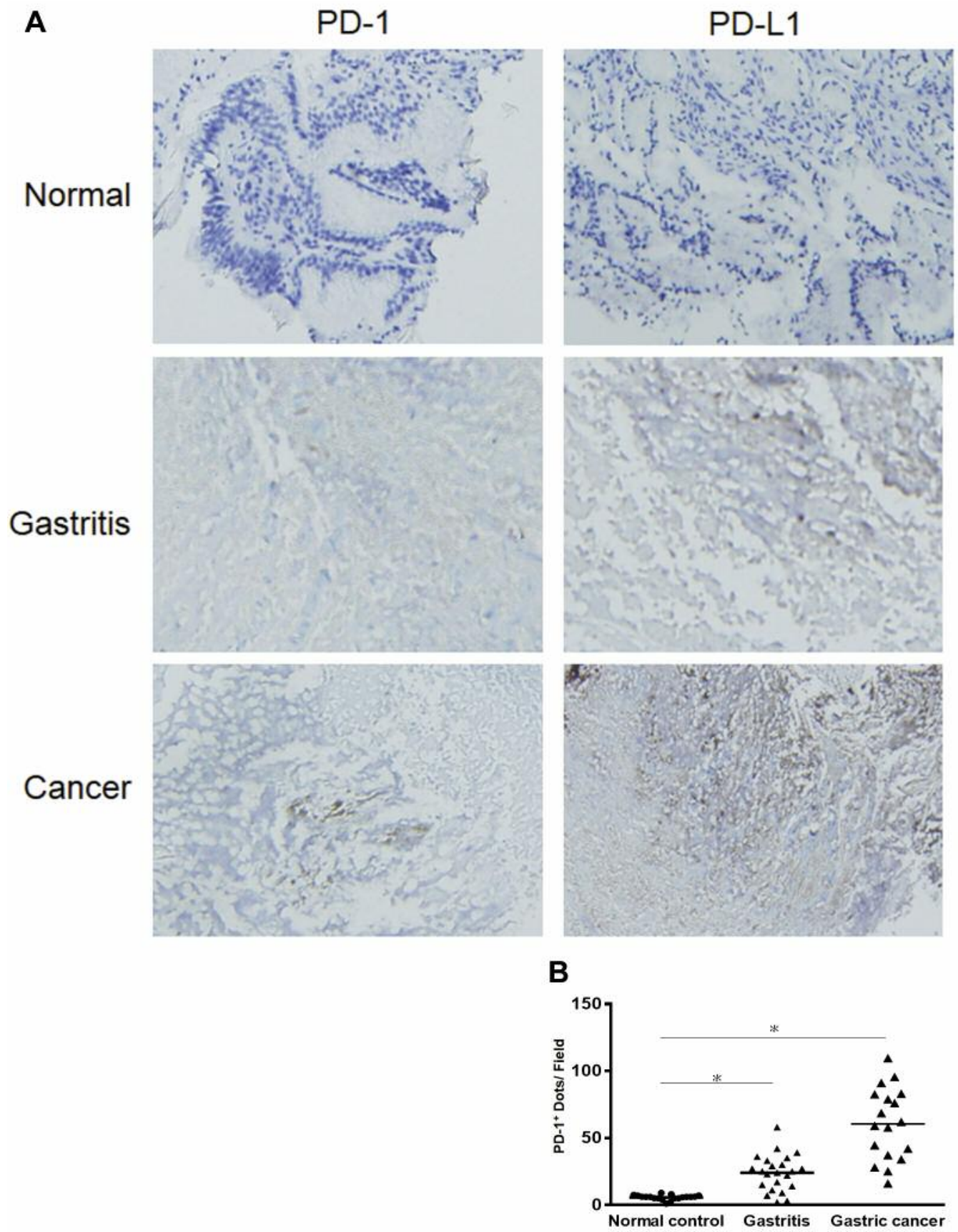

Figure 2. The in situ expression of PD-1/PD-L1 by immunohistochemical staining. (A) Photomicrographs of immunohistochemical staining of PD-1 and PD-L1 in stomach sections. Arrows indicate PD-1 positive lymphocytes. (B) Quantitative results with statistical analysis for PD-1-positive dots in normal control $(n=19)$, gastritis $(n=23)$ and gastric adenocarcinoma $(n=18)$ groups. The data were collected at $200 \times$ power by two different investigators. One dot indicates one section from one patient. Black bars indicate the mean value. ${ }^{*} p<0.05$.

1/PD-L1. As shown in Figure 2A, expression of PD-1 and PDL1 was greater in tumor sections than in biopsy specimens from patients with gastritis and asymptomatic controls. In particular, PD-1 was expressed mainly on lymphocytes and
PD-L1 was mainly expressed on gastric adenocarcinoma epithelial cells (Figure 2A). Quantitative analysis showed that gastric adenocarcinoma patients expressed more PD-1 than patients with gastritis and normal controls (Figure 2B) subjects. 
A
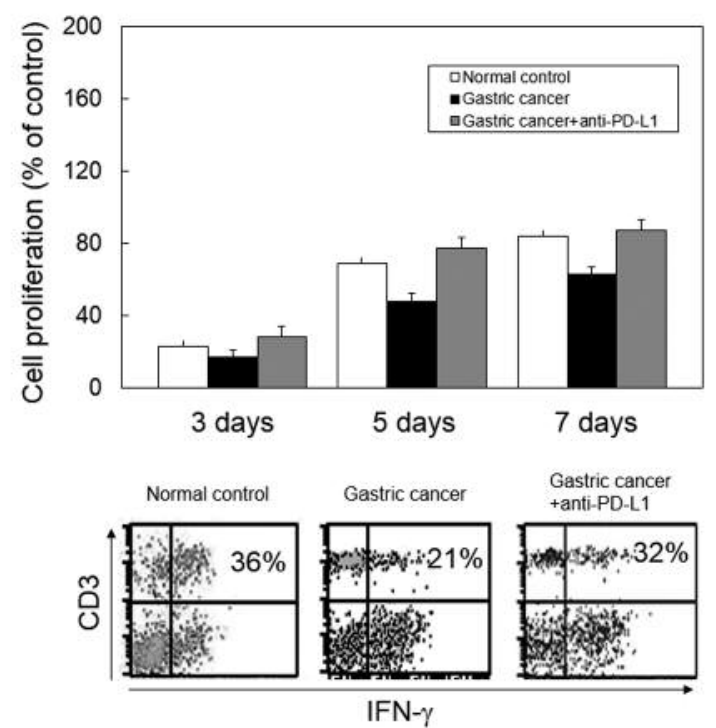

B

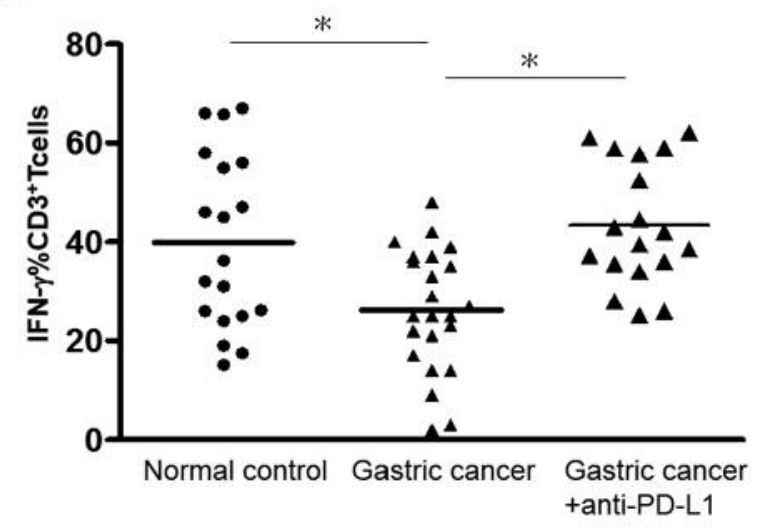

Figure 3. Proliferation and IFN- $\gamma$-production by $\mathrm{CD}^{+}{ }^{+} \mathrm{T}$ cells increased with inhibition of PD-L1. (A) PBMC from normal control $(n=19)$ and gastric adenocarcinoma $(n=18)$ were stimulated with $\alpha-C D 3$ $(1 \mu \mathrm{g} / \mathrm{ml}) / \alpha-C D 28(1 \mu \mathrm{g} / \mathrm{ml})$ in the presence or absence of blocking antibody against PD-L1. The summarized results with statistical analysis for $\mathrm{CD}^{+} T$ cell proliferation are shown. (B) Numbers on the upper right corners are the frequencies of IFN- $\gamma^{+} C D 3^{+} T$ cells. PBMC from normal control and gastric adenocarcinoma were stimulated with PMA $(50 \mathrm{ng} / \mathrm{ml})$ and ionomycin $(1 \mu \mathrm{g} / \mathrm{ml})$ for $6 \mathrm{~h}$ and monensin $(2 \mu \mathrm{M})$ was supplemented after the first hour. The cells were then harvested for intracellular IFN- $\gamma$ staining as shown by representative data in (B) top. Lower shows the combined results with statistical analysis. The black bars indicate the mean values. ${ }^{*} p<0.05$.

Blocking PD-L1 restores the proliferative ability of and IFN- $\gamma$ production in $\mathrm{CD}^{+} T$ cells. To investigate the impact of the PD-1/PD-L1 pathway on $\mathrm{CD}^{+} \mathrm{T}$ cells in gastric adenocarcinoma, PBMC from normal controls and patients with gastric adenocarcinoma were stimulated in the absence or presence of blocking antibody against PD-L1 ( $\alpha-\mathrm{PD}-\mathrm{L} 1)$.
Results showed that blocking the pathway could largely enhance the proliferative capacity of $\mathrm{CD}^{+} \mathrm{T}$ cells in gastric adenocarcinoma from $72 \mathrm{~h}$ (Figure $3 \mathrm{~A}$ ). It was also found that the percentage of IFN- $\gamma$-producing $\mathrm{CD}^{+} \mathrm{T}$ cells in gastric adenocarcinoma increased in the presence of $\alpha$-PDL1 to the level of that in normal controls (Figure 3B). Therefore, these data confirm previous reports that blocking PD-L1 could restore the capacities of proliferation and IFN$\gamma$ production of $\mathrm{CD}^{+} \mathrm{T}$ cells, which are impaired in gastric adenocarcinoma.

$C D 3^{+} T$-cell produced IFN- $\gamma$ can induce PD-LI expression on gastric adenocarcinoma cells. Some studies have demonstrated that IFN- $\gamma$ could induce PD-L1 expression. We performed a series of parallel experiments to verify whether PD-L1-up-regulation could be triggered by IFN- $\gamma$ released from $\mathrm{CD}^{+} \mathrm{T}$-cells. Results showed that both IFN- $\gamma$ and coculturing with $\mathrm{CD}^{+} \mathrm{T}$ cells could increase PD-L1 expression on primary gastric adenocarcinoma epithelial cells after 6 hours of treatment. PD-L1 expression gradually increased during the entire 24-h period of in vitro incubation, whereas blocking IFN- $\gamma$ inhibited the up-regulation (Figure 4A). Thus, up-regulation of PD-L1 is triggered by $\mathrm{CD}^{+}$cells in an IFN- $\gamma$-dependent mechanism.

IFN- $\gamma$ facilitates resistance of primary gastric adenocarcinoma epithelial cells to $C D 3^{+} T$ cells. In order to investigate whether IFN- $\gamma$-treated primary gastric adenocarcinoma epithelial cells could weaken the cytotoxic effect of $\mathrm{T}$ cells, the $\mathrm{CD}^{+} \mathrm{T}$ cells isolated from gastric adenocarcinoma subjects were co-cultured with primary gastric adenocarcinoma epithelial cells at different ratios in the presence or absence of PD-L1 blocking antibody. After 24 hours of stimulation, the cells were harvested to evaluate necrosis by 7-AAD staining. The results showed that the IFN- $\gamma$-treated primary gastric adenocarcinoma epithelial cells were much more resistant to necrosis than the controls at all effector to target $(\mathrm{E} / \mathrm{T})$ ratios. Blocking PD-L1 reversed the sensitivity of primary gastric adenocarcinoma epithelial cells to $\mathrm{CD}^{+} \mathrm{T}$ cell-dependent cytotoxicity (Figure $4 \mathrm{~B}$ ).

Primary gastric adenocarcinoma epithelial cells promote $C D 3^{+} T$ cell apoptosis by $P D-L 1$ up-regulation. We further investigated whether IFN- $\gamma$-treated primary gastric adenocarcinoma epithelial cells could promote the apoptosis or necrosis of $\mathrm{CD}^{+} \mathrm{T}$ cells. Our data showed that apoptosis (Annexin- $\mathrm{V}^{+}$, Figure $4 \mathrm{C}$ upper panel) and necrosis $\left(7-\mathrm{AAD}^{+}\right.$, Figure $4 \mathrm{C}$ lower panel) of $\mathrm{CD}^{+} \mathrm{T}$ cells significantly increased when cells were co-cultured with IFN- $\gamma$-treated primary gastric adenocarcinoma epithelial cells. Blocking PD-L1 largely inhibited apoptosis and necrosis of $\mathrm{CD}^{+} \mathrm{T}$ cells induced by IFN- $\gamma$-treated primary gastric adenocarcinoma epithelial cells (Figure 4C). In order to see whether IFN- $\gamma$ levels differed 
A

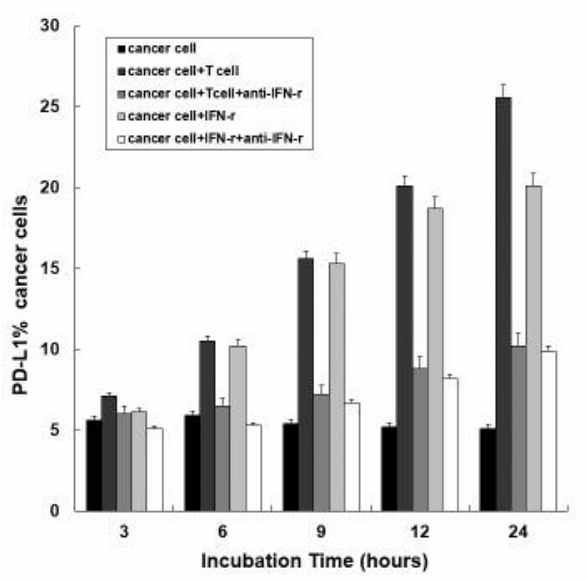

C
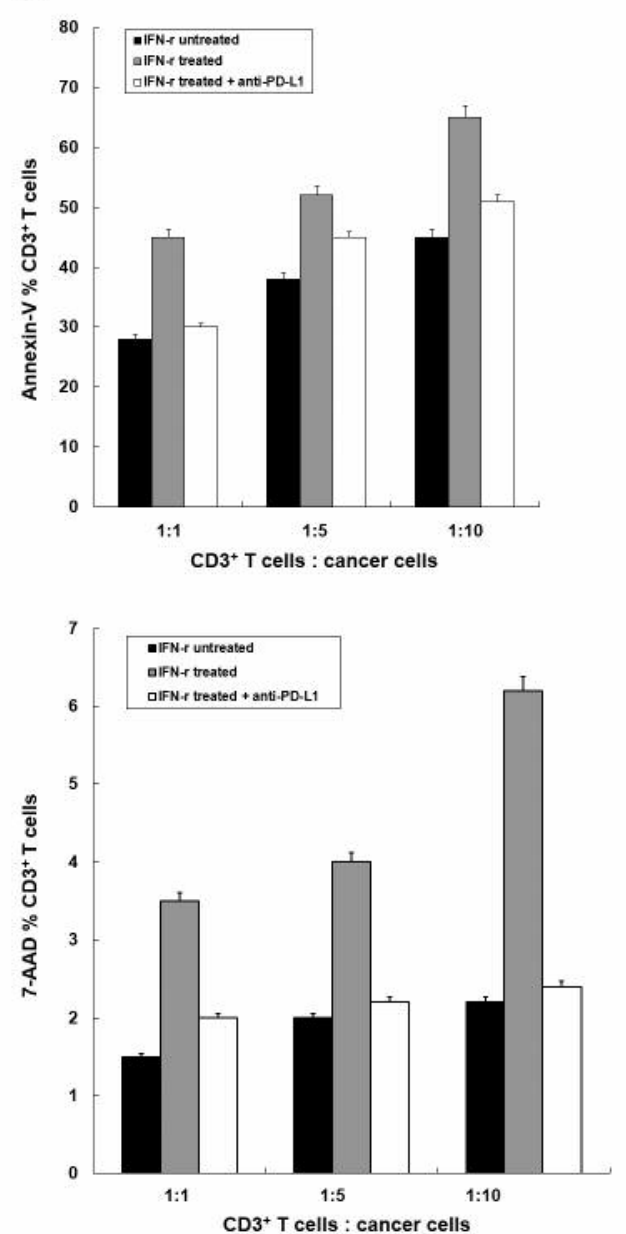

B

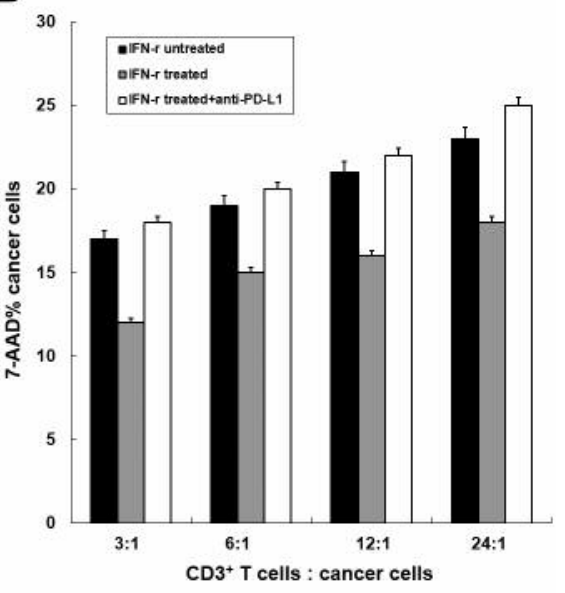

D

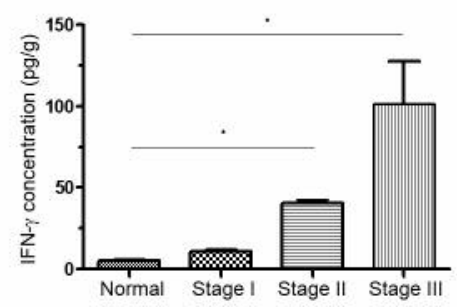

$\mathbf{E}$

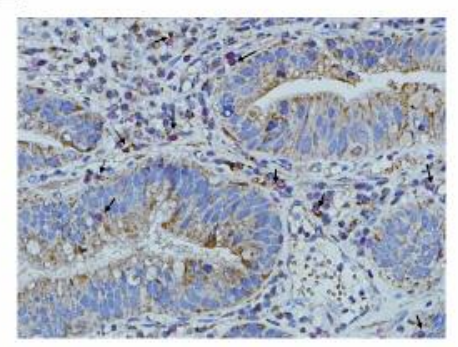

Figure 4. IFN- $\gamma$-treated primary gastric adenocarcinoma epithelial cells promotes $C D 3^{+} T$-cell apoptosis. (A) $C D 3^{+} T$ cells up-regulate PD-L1 expression on primary gastric adenocarcinoma epithelial cells in an IFN- $\gamma$-dependent manner. (B) IFN- $\gamma$-treated primary gastric adenocarcinoma epithelial cells were much more resistant to $C D 3^{+} T$ cell-dependent cytotoxicity. (C) IFN- $\gamma$-treated primary gastric adenocarcinoma epithelial cells promoted $C D 3^{+} T$ cells apoptosis (Annexin- $V^{+}$, upper panel) and necrosis $\left(7 A A D^{+}\right.$, lower panel) by a PD-L1-dependent pathway. At least five trials were run in the above experiments. (D) The IFN- $\gamma$ concentration increased significantly in non-tumor tissue in stage III, compared stage I and healthy control tissue. (HC, $n=6$; stage I, $n=6$; stage II, $n=7$; stage III, $n=5)$. The data indicate mean values $\pm S D$. ${ }^{*} p<0.05$. (E) CD3/cleaved caspase-3 double stainings in situ were measured in tumor sections (red for CD3, brown for cleaved caspase-3). Arrows show double-positive cells. 

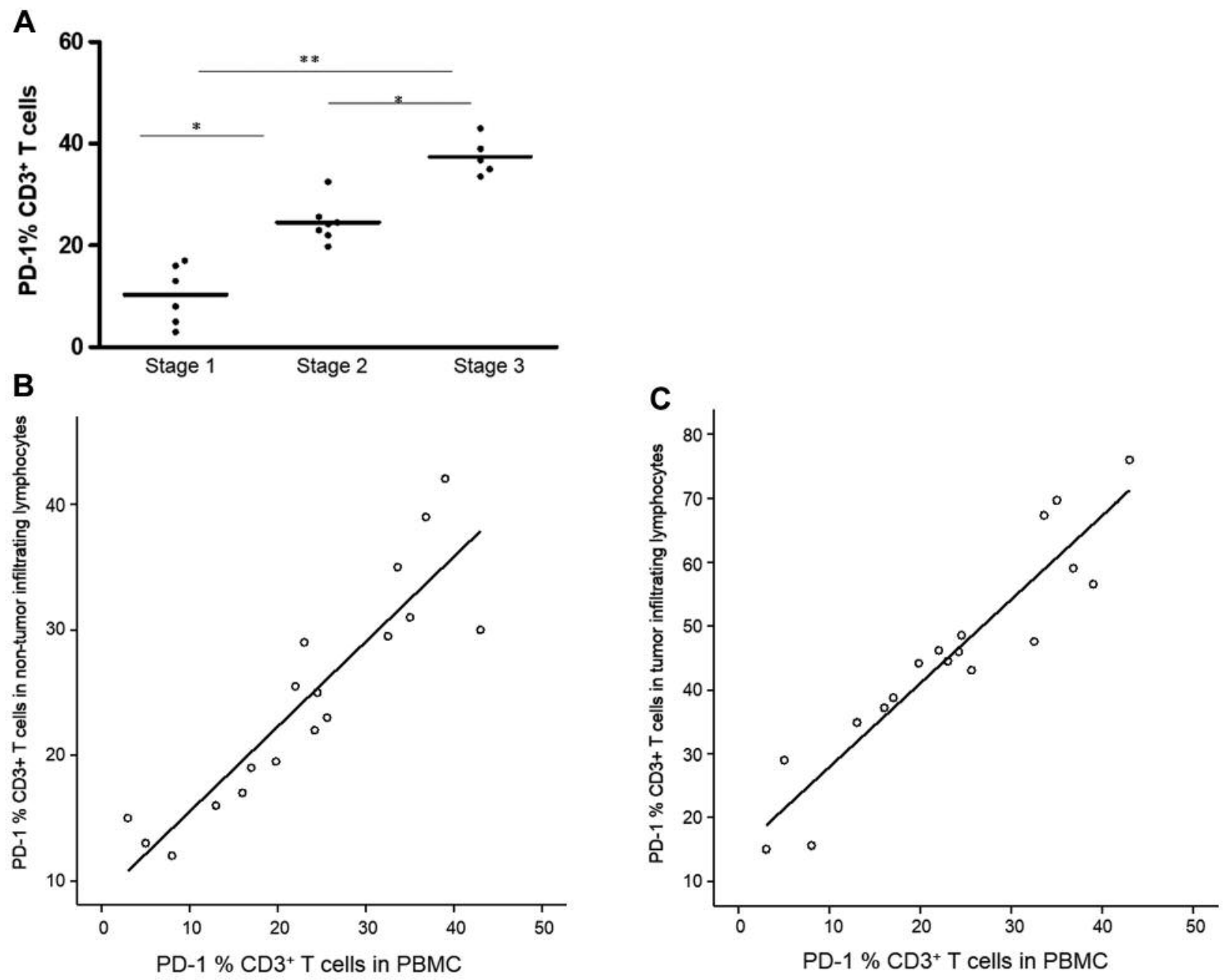

Figure 5. PD-1 expression correlates with prognosis of gastric adenocarcinoma. (A) percentages of peripheral blood PD-1 on CD3+T cells according to different clinical stages of gastric adenocarcinoma (stage I, $n=6$; stage II, $n=7$; stage III, $n=5$ ) are shown. Black bars indicate mean values. ${ }^{*} p<0.05 . * * p<0.005 . P D-1$ expression in PBMCs positively correlated (Spearman rank test) with expression in corresponding non-tumor infiltrating lymphocytes $(B)$ and tumor infiltrating lymphocytes $(C)$.

between controls and patients with differing stages of gastric adenocarcinoma, the concentrations of IFN- $\gamma$ in the supernatant of tissue homogenates were measured by ELISA. The results showed that IFN- $\gamma$ was significantly higher in non-tumor tissue from patients with stage III gastric adenocarcinoma than in patients with stage I gastric adenocarcinoma and normal control tissue (Figure 4D). Furthermore, there were no significant differences among the three stages of tumor tissue in gastric adenocarcinoma. However, apoptosis of $\mathrm{T}$ cells in tumor tissues was determined by staining with anti-cleavedcaspase-3 antibodies; most infiltrating $\mathrm{T}$ cells around or primarily inside the tumor nest were apoptotic (Figure 4E).

PD-1 correlate with disease progression in gastric adenocarcinoma. In this study, we found that expression of
PD $-1^{+} \mathrm{CD}^{+} \mathrm{T}$ cells in peripheral blood positively correlated with disease progression in gastric adenocarcinoma, and reached the highest level in stage III patients (Figure 5A). We further analyzed the relationship of PD-1 expression between PBMC and corresponding stomach tissues. The PD-1 expression in PBMC positively correlated with that in non-tumor infiltrating lymphocytes and in tumor infiltrating lymphocytes (Figure 5B and C).

\section{Discussion}

The interaction between PD-1 and PD-L1 has been demonstrated to negatively regulate T-cell activation and functions, leading to inhibition of the immune response in cancer patients. However, little is known about how the PD- 
1/PD-L1 pathway operates between $\mathrm{CD}^{+} \mathrm{T}$ cells and tumor cells in gastric adenocarcinoma patients. Here, we characterized the profile of PD-1 expression in gastric adenocarcinoma patients, and found a significant increase in peripheral blood and gastric infiltrating PD-1 expression, which would promote apoptosis of $\mathrm{CD}^{+} \mathrm{T}$ cells that come into contact with gastric adenocarcinoma epithelial cells. Moreover, the increased peripheral blood and gastric infiltrating PD $-1^{+} \mathrm{CD} 3^{+} \mathrm{T}$ cells might be predictive of poorer disease progression. These data extend our understanding of the PD-1/PD-L1 interaction between gastric adenocarcinoma epithelial cells and $\mathrm{CD}^{+} \mathrm{T}$ cells during the anti-tumor response in gastric adenocarcinoma patients.

In this study, we first found that PD-1 was markedly upregulated on tumor infiltrating lymphocytes, especially on effector-phase $\mathrm{CD}^{+} \mathrm{T}$ cells. PD- 1 has been shown to inhibit anti-tumor immunity at the effector phase (6). The increased PD-1 expression found in our study might account for the poor prognosis of patients with gastric adenocarcinoma. Furthermore, central memory $\mathrm{CD}^{+} \mathrm{T}$ cells have been reported to confer superior anti-tumor immunity (20). Our study found that $\mathrm{CCR}^{+} \mathrm{CD} 45 \mathrm{RA}^{-}(\mathrm{Tcm})$ were decreased in tumor infiltrating lymphocytes. Two possible mechanisms can account for the decreased Tcm in tumor infiltrating lymphocytes: the Tcm may have converted to Tem before being recruited into the tumor infiltrating region, or the Tcm were much more prone to apoptosis than Tem with upregulated PD-1 expression. Similar up-regulation of PD-1 expression was also observed in several other cancers, including hepatocellular carcinoma, melanoma, prostate cancer and renal cancer $(8,17,21,22)$. PD-1 up-regulation on T cells may be due to TCR activation $(23,24)$ by tumorassociated antigens or stimulation by common $\gamma$-chain cytokines (25) in the tumor microenvironment.

The relationship between tumor-associated PD-L1 and pathological features has been recently studied in several cancers, and it was found that patients with cancer cells that overexpress PD-L1 had significantly poorer prognosis than those with cancer cells that underexpress PD-L1 (12, 13, 26, 27). Similar results were also found in our study. Although the detection of PD-L1 requires an invasive biopsy procedure and would be a complex test for clinical application, it is worth investigating whether PD-1 expression can predict the prognosis of gastric adenocarcinoma patients. Therefore, we further evaluated the validity of peripheral blood PD-1 in predicting the prognosis of gastric adenocarcinoma patients. Our data showed that the frequency of PD $-1^{+} \mathrm{CD} 3^{+} \mathrm{T}$ cells in the peripheral blood in stage III gastric adenocarcinoma patients was twice that in stage $\mathrm{I}$, suggesting that $\mathrm{CD} 3^{+} \mathrm{T}$ cells in advanced stages of disease were prone to be functionally impaired. We further analyzed PD-1 expression in PBMC, non-tumor infiltrating lymphocytes and tumor infiltrating lymphocytes simultaneously in a total of eighteen patients. We found that PD-1 expression in peripheral blood positively correlated with that in non-tumor infiltrating lymphocytes and tumor infiltrating lymphocytes.

In vitro functional assay showed that blocking PD-L1 could enhance $\mathrm{CD}^{+} \mathrm{T}$ cell proliferation and IFN- $\gamma$ secretion. Although the precise mechanism regulating PD-L1 expression in tumor cells is unknown, several cytokines, including IFN- $\gamma$ and TNF- $\alpha$ have been implicated as potent inducers of PD-L1 expression on the surface of several tumor cells $(28,29)$. We also found similar results in the human gastric adenocarcinoma cell line AGS (16). In this study, we found that $\mathrm{CD}^{+} \mathrm{T}$ cells could stimulate primary gastric adenocarcinoma epithelial cells to up-regulate PD-L1 by an IFN- $\gamma$-dependent mechanism, which may facilitate primary gastric adenocarcinoma cellular resistance to $\mathrm{CD} 3^{+} \mathrm{T}$-dependent cytotoxicity and conversely induce $\mathrm{CD} 3^{+} \mathrm{T}$ cells apoptosis. Here, the up-regulation of PD-L1 might be one negative feedback reaction, which is fully utilized by gastric adenocarcinoma cells to escape from immune surveillance. We found that IFN- $\gamma$ was up-regulated in non-tumor tissues from stage III gastric adenocarcinoma patients, which was coincident with PD-L1 up-regulation in the tumor tissues. However, such differences were not found in the peripheral blood. The data also showed that IFN- $\gamma$ concentrations in tumor tissues were very low, which was due to quick absorption by tumor cells within 6 hours (Figure 4A), and narrow or disappeared interspaces within the tumor nest. In addition, incubation with $\alpha$-PD-L1 reduced primary gastric adenocarcinoma epithelial cellinduced apoptosis of $\mathrm{CD}^{+} \mathrm{T}$ cells and increased the cytotoxicity of $\mathrm{CD}^{+} \mathrm{T}$ cells.

Collectively, induction of PD-L1 may be one mechanism for immune evasion used by tumors for attenuating T-cell responses and promoting anti-tumor effector $\mathrm{CD}^{+} \mathrm{T}$-cell apoptosis. Furthermore, our data demonstrated that $\mathrm{CD}^{+} \mathrm{T}$ cells could make two distinct impacts on gastric adenocarcinoma cells: eradicate the gastric adenocarcinoma epithelial cells or induce PD-L1 expressions on gastric adenocarcinoma epithelial cells. As a result, a crucial part of the anti-tumor response seemed to be whether the $\mathrm{CD}^{+} \mathrm{T}$ cells can secrete sufficient amounts of IFN- $\gamma$ before the upregulation of PD-L1 on gastric adenocarcinoma epithelial cells. If true, more experiments should be carried out to determine this effective level of IFN- $\gamma$.

In this study we described for the first time the role of the PD-1/PD-L1 pathway in the interaction between gastric adenocarcinoma epithelial cells and $\mathrm{CD}^{+} \mathrm{T}$ cells in gastric adenocarcinoma patients. We demonstrated that PD-1/PD-L1 plays a pivotal role in tumor evasion, and blocking interaction with anti-PD-L1 antibody would revitalize $\mathrm{CD}^{+} \mathrm{T}$ cells to give them a second chance to clear the tumor. Moreover, both peripheral and gastric infiltrating PD-1 
expressions could act as prognostic markers in patients with gastric adenocarcinoma. Further understanding of the immunopathogenesis of gastric adenocarcinoma will be critically important for the development of effective therapeutic strategies against the disease.

\section{Conflicts of Interest}

The Authors declare no conflicts of interest

\section{Acknowledgements}

This work was supported by Grants from the National Science Council, Taiwan (NSC 98-2320-B-039-012-MY3) and Changhua Christian Hospital, Changhua, Taiwan (106-CCH-IRP-055). The Authors would like to thank Dr. Mei-Tu Yang (Chief of General Surgery, Surgical Department) for his valuable technique assistance and critical review of the manuscripts.

\section{References}

1 Ferlay J, Soerjomataram I, Dikshit R, Eser S, Mathers C, Rebelo M, Parkin DM, Forman D and Bray F: Cancer incidence and mortality worldwide: Sources, methods and major patterns in globocan 2012. Int J Cancer 136(5): E359-386, 2015.

2 Elimova E, Shiozaki H, Wadhwa R, Sudo K, Chen Q, Estrella JS, Blum MA, Badgwell B, Das P, Song S and Ajani JA: Medical management of gastric cancer: A 2014 update. World J Gastroenterol 20(38): 13637-13647, 2014.

3 Granier C, De Guillebon E, Blanc C, Roussel H, Badoual C, Colin E, Saldmann A, Gey A, Oudard S and Tartour E: Mechanisms of action and rationale for the use of checkpoint inhibitors in cancer. ESMO Open 2(2): e000213, 2017.

4 Francisco LM, Sage PT and Sharpe AH: The pd-1 pathway in tolerance and autoimmunity. Immunological reviews 236: 219 $242,2010$.

5 Yamazaki T, Akiba H, Iwai H, Matsuda H, Aoki M, Tanno Y, Shin T, Tsuchiya H, Pardoll DM, Okumura K, Azuma M and Yagita $\mathrm{H}$ : Expression of programmed death 1 ligands by murine t cells and apc. J Immunol 169(10): 5538-5545, 2002.

6 Ostrand-Rosenberg S, Horn LA and Haile ST: The programmed death-1 immune suppressive pathway: Barrier to anti-tumor immunity. J Immunol 193(8): 3835-3841, 2014.

7 Yamamoto R, Nishikori M, Kitawaki T, Sakai T, Hishizawa M, Tashima M, Kondo T, Ohmori K, Kurata M, Hayashi T and Uchiyama T: Pd-1-pd-1 ligand interaction contributes to immunosuppressive microenvironment of hodgkin lymphoma. Blood 111(6): 3220-3224, 2008

8 Thompson RH, Dong H, Lohse CM, Leibovich BC, Blute ML, Cheville JC and Kwon ED: Pd-1 is expressed by tumorinfiltrating immune cells and is associated with poor outcome for patients with renal cell carcinoma. Clin Cancer Res 13(6): 1757-1761, 2007

9 Hamanishi J, Mandai M, Iwasaki M, Okazaki T, Tanaka Y, Yamaguchi K, Higuchi T, Yagi H, Takakura K, Minato N, Honjo $\mathrm{T}$ and Fujii S: Programmed cell death 1 ligand 1 and tumorinfiltrating $\mathrm{cd} 8^{+} \mathrm{t}$ lymphocytes are prognostic factors of human ovarian cancer. Proc Natl Acad Sci USA 104(9): 3360-3365, 2007.
10 Shi F, Shi M, Zeng Z, Qi RZ, Liu ZW, Zhang JY, Yang YP, Tien $\mathrm{P}$ and Wang FS: Pd-1 and pd-11 up-regulation promotes cd8(+) t-cell apoptosis and postoperative recurrence in hepatocellular carcinoma patients. Int J Cancer 128(4): 887-896, 2011.

11 Nomi T, Sho M, Akahori T, Hamada K, Kubo A, Kanehiro H, Nakamura S, Enomoto K, Yagita H, Azuma M and Nakajima Y: Clinical significance and therapeutic potential of the programmed death-1 ligand/programmed death-1 pathway in human pancreatic cancer. Clin Cancer Res 13(7): 2151-2157, 2007.

12 Nakanishi J, Wada Y, Matsumoto K, Azuma M, Kikuchi K and Ueda S: Overexpression of b7-h1 (pd-11) significantly associates with tumor grade and postoperative prognosis in human urothelial cancers. Cancer Immunol Immunother 56(8): 1173-1182, 2007.

13 Ghebeh H, Mohammed S, Al-Omair A, Qattan A, Lehe C, AlQudaihi G, Elkum N, Alshabanah M, Bin Amer S, Tulbah A, Ajarim D, Al-Tweigeri T and Dermime S: The b7-h1 (pd-11) t lymphocyte-inhibitory molecule is expressed in breast cancer patients with infiltrating ductal carcinoma: Correlation with important high-risk prognostic factors. Neoplasia 8(3): 190-198, 2006.

14 Wu YY, Tsai HF, Lin WC, Hsu PI, Shun CT, Wu MS and Hsu PN: Up-regulation of $\operatorname{ccl} 20$ and recruitment of ccr6 ${ }^{+}$gastric infiltrating lymphocytes in helicobacter pylori gastritis. Infect Immun 75(9): 4357-4363, 2007.

15 Wu YY, Tsai HF, Lin WC, Chou AH, Chen HT, Yang JC, Hsu PI and Hsu PN: Helicobacter pylori enhances tumor necrosis factor-related apoptosis-inducing ligand-mediated apoptosis in human gastric epithelial cells. World J Gastroenterol 10(16): 2334-2339, 2004.

16 Wu YY, Lin CW, Cheng KS, Lin C, Wang YM, Lin IT, Chou YH and Hsu PN: Increased programmed death-ligand-1 expression in human gastric epithelial cells in Helicobacter pylori infection. Clinical \& Experimental Immunology 161(3): 551-559, 2010.

17 Hsu PN, Yang TC, Kao JT, Cheng KS, Lee YJ, Wang YM, Hsieh $\mathrm{CT}$, Lin CW and Wu YY: Increased pd-1 and decreased cd28 expression in chronic hepatitis b patients with advanced hepatocellular carcinoma. Liver Int 30(9): 1379-1386, 2010.

18 Wu Y-Y, Chen J-H, Kao J-T, Liu K-C, Lai C-H, Wang Y-M, Hsieh C-T, Tzen JTC and Hsu P-N: Expression of cd25(high) regulatory $\mathrm{t}$ cells and $\mathrm{pd}-1$ in gastric infiltrating cd4(+) $\mathrm{t}$ lymphocytes in patients with helicobacter pylori infection. Clin Vaccine Immunol 18(7): 1198-1201, 2011.

19 Smoot DT, Sewchand J, Young K, Desbordes BC, Allen CR and Naab T: A method for establishing primary cultures of human gastric epithelial cells. Methods Cell Sci 22(2-3): 133-136, 2000.

20 Klebanoff CA, Gattinoni L, Torabi-Parizi P, Kerstann K, Cardones AR, Finkelstein SE, Palmer DC, Antony PA, Hwang ST, Rosenberg SA, Waldmann TA and Restifo NP: Central memory self/tumor-reactive $\mathrm{cd}^{+} \mathrm{t}$ cells confer superior antitumor immunity compared with effector memory t cells. Proc Natl Acad Sci USA 102(27): 9571-9576, 2005.

21 Ahmadzadeh M, Johnson LA, Heemskerk B, Wunderlich JR, Dudley ME, White DE and Rosenberg SA: Tumor antigenspecific cd8 t cells infiltrating the tumor express high levels of pd-1 and are functionally impaired. Blood 114(8): 1537-1544, 2009.

22 Ebelt K, Babaryka G, Frankenberger B, Stief CG, Eisenmenger W, Kirchner T, Schendel DJ and Noessner E: Prostate cancer lesions are surrounded by foxp $3^{+}, \mathrm{pd}-1^{+}$and $\mathrm{b} 7-\mathrm{h} 1^{+}$lymphocyte clusters. Eur J Cancer 45(9): 1664-1672, 2009. 
23 Agata Y, Kawasaki A, Nishimura H, Ishida Y, Tsubata T, Yagita $\mathrm{H}$ and Honjo T: Expression of the pd-1 antigen on the surface of stimulated mouse $\mathrm{t}$ and b lymphocytes. Int Immunol $8(5)$ : 765-772, 1996

24 Nishimura H, Agata Y, Kawasaki A, Sato M, Imamura S, Minato $\mathrm{N}$, Yagita H, Nakano T and Honjo T: Developmentally regulated expression of the pd-1 protein on the surface of double-negative (cd4-cd8-) thymocytes. Int Immunol 8(5): 773-780, 1996.

25 Kinter AL, Godbout EJ, McNally JP, Sereti I, Roby GA, O'Shea MA and Fauci AS: The common gamma-chain cytokines il-2, il7 , il-15, and il-21 induce the expression of programmed death1 and its ligands. J Immunol 181(10): 6738-6746, 2008.

26 Gao Q, Wang XY, Qiu SJ, Yamato I, Sho M, Nakajima Y, Zhou J, Li BZ, Shi YH, Xiao YS, Xu Y and Fan J: Overexpression of pd-11 significantly associates with tumor aggressiveness and postoperative recurrence in human hepatocellular carcinoma. Clin Cancer Res 15(3): 971-979, 2009.

27 Inman BA, Sebo TJ, Frigola X, Dong H, Bergstralh EJ, Frank I, Fradet Y, Lacombe L and Kwon ED: Pd-11 (b7-h1) expression by urothelial carcinoma of the bladder and bcg-induced granulomata: Associations with localized stage progression. Cancer 109(8): 1499-1505, 2007.
28 Muhlbauer M, Fleck M, Schutz C, Weiss T, Froh M, Blank C, Scholmerich $\mathrm{J}$ and Hellerbrand C: Pd-11 is induced in hepatocytes by viral infection and by interferon-alpha and -gamma and mediates t cell apoptosis. J Hepatol 45(4): 520-528, 2006.

29 He YF, Wang XH, Zhang GM, Chen HT, Zhang H and Feng ZH: Sustained low-level expression of interferon-gamma promotes tumor development: Potential insights in tumor prevention and tumor immunotherapy. Cancer Immunol Immunother 54(9): 891897, 2005.
Received February 7, 2018

Revised February 20, 2018

Accepted February 21, 2018 